\title{
Projeto Arcade: Desenvolvimento de Jogos Na Atuação De Um Futuro Melhor Através da Informática e Cidadania.
}

\author{
Francisco M. A. de Araújo ${ }^{1}$ \\ Deymes S. de Aguiar ${ }^{1}$, Matheus A. Dantas ${ }^{1}$, Luize C. da Silva ${ }^{1}$, Wellynson L. A. Soares ${ }^{1}$ \\ Marcos V. C. B. Nunes ${ }^{1}$ \\ ${ }^{1}$ Instituto Federal de Educação, Ciência e Tecnologia do Piauí - Campus Teresina Central, \\ Piauí - Brasil

\begin{abstract}
francisco.marcelinodifpi.edu.br, Deymes@ifpi.edu.br, matheussdantas19@gmail.com, marcosvitorcastelo@gmail.com

luizecristinal@gmail.com, wellynson.soares@ifpi.edu.br,
\end{abstract}

\begin{abstract}
The Arcade Project is based on an arcade machine, which aims through entertainment to foster local production of games development. The project offers a game development course for public school students, as such courses are not easily found. As a result, students will have to create a game in order to be machine-driven, providing game development education that encompasses computer skills, entrepreneurship, marketing, and teamwork, giving the graduate student an entrepreneurial vision. Accompanied by an Internet of Things (IoT) system, providing full transparency of all acquired features and game metrics as feedback to developers.
\end{abstract}

Resumo. O Projeto Arcade baseia-se em uma máquina de fliperama, que visa através do entretenimento fomentar a produção local de desenvolvimento de jogos eletrônicos (games). O projeto oferece um curso de desenvolvimento de games para alunos de escolas públicas, uma vez que tais cursos não são encontrados facilmente. Por conseguinte, os alunos terão de criar um jogo, afim de ser indroduzido na máquina, proporcionando o ensino sobre desenvolvimento de jogos abrangendo conhecimentos da computação, empreendedorismo, marketing e trabalho em equipe, dando ao aluno formado uma visão empreededora. Acompanhado de um sistema de IoT (Internet Of Things), informando total transparência de todos os recursos adquiridos e métricas dos jogos servindo de feedback para os desenvolvedores.

\section{Visão Geral}

Atualmente, os games vêm se tornando uma forma de negócio e entretenimento muito forte no mundo [Fardo 2013], tanto para crianças como para jovens e adultos [Savi and Ulbricht 2008]. No Brasil, o impacto dessa indústria não é diferente, uma vez que grande parte da população brasileira é consumidora de jogos eletrônicos [Fardo 2013]. Dessa forma, com o crescimento no mercado, os jogos vêm se destacando em diversas áreas, como por exemplo: na área da saúde, no qual há o desenvolvimento de jogos específicos ou a adaptação de outros para auxiliar profissionais em processos de reablitação (Gameterapia), além de serem utilizados como ferramentas de aprendizagem em diversos campus de estudos e pesquisas, como os jogos educativos e as disciplinas de física e programação que abordam conteúdos indispensáveis para a criação de games 
VIII Congresso Brasileiro de Informática na Educação (CBIE 2019)

Anais do VIII Workshop de Desafios da Computação aplicada à Educação (DesafIE 2019)

[Rapkiewicz et al. 2007] [Bomfoco and de Abreu Azevedo 2012]. Nessa perspectiva, é possível observar o crescimento do mercado de games, tendo em vista que a sua utilização ampliou-se positivamente, indo além de uma forma de entretenimento individual ou coletivo e contribuindo em outras áreas do conhecimento, servindo de auxílio ou incentivo para a realização de determinadas tarefas ou no alcançe de certos objetivos e metas. Desse modo, o desenvolvimento de jogos vem ganhando reconhecimento e importância em diversas áreas e no mundo todo, criando oportunidades de negócio para jovens e adultos desenvolvedores de games [Silva et al. 2016].

Portanto, o Projeto Arcade oferece oportunidade para os aspirantes e/ou desenvolvedores de games; tratando-se de uma máquina de fliperama alimentada por jogos feitos por estudantes de escolas públicas, e que para garantir o desenvolvimento desses games, os autores do projeto disponibilizarão um curso gratuito com as principais game engines da atualidade. O projeto foi aprovado no edital $n^{\circ} 82$ de 27/06/2017 PIBIC Jr IT, aberto no Instituto Federal do Piaú, e segue em desenvolvimento pelo LABIRAS, Laboratório de Inovação e Pesquisa Aplicada situado no IFPI - Campus Teresina Central, onde possui portfólio e reconhecimento por trabalahar com pesquisa e desenvolvimento de projetos nas áreas de robótica e games.

\section{Trabalho Proposto}

O Projeto Arcade baseia-se em uma máquina de fliperama, com o objetivo de fomentar o desenvolvimento de jogos local, ofertando ao desenvolvedores iniciantes uma oportunidade de começar um negócio através de cursos fornecidos para a comunidade. Ao final do curso, os alunos deverão apresentar um protótipo, no qual os melhores receberão total apoio para a sua finalização e posteriormente, sua implementação na máquina de fliperama. O projeto busca ensinar por meio da Aprendizagem Baseada em Projetos (PBL), um modelo de ensino que possibilita o aluno a superar obstáculos e estimular o trabalho em equipe, a fim de encontrar uma solução para as dificuldades na crição de jogos[Bender 2015]. Através de Iot (Internet of Things), a máquina auxilia os autores dos jogos introduzidos na mesma, fornecendo uma série de informacões (dados e métricas) sobre o acesso dos games para os desenvolvedores, a fim de obter um melhor feedback.

\section{Resultados e Concluções}

Ao término do projeto, foi analisado a máquina de fliperama construída em MDF (Medium-Density Fiberboard ou placa de fibra de média densidade, em português), composta por botões, joysticks e uma moedeira. Com a máquina finalizada, realizou-se testes dentro do próprio instituto para validar o projeto, onde particparam 45 alunos do ensino médio, dentre eles $64,4 \%$ eram meninos e $35,6 \%$ eram meninas, o feedback dos estudantes foi bastante positivo, podendo perceber que a introdução do projeto trouxe entretenimento e sastifação para todos os que se propuseram a participar da fase de testes.

Após a finalização dos testes, o projeto foi apresentado para a banca de Bolsas de Iniciação Científica para Ensino Médio (PIBIC JR IT), onde obteve aprovação siginificante por ser um projeto inovador que remete a uma causa social, uma vez que além de lidar com o entretenimento, oferece cursos gratuitos de desenvolvimento de jogos para aqueles que ainda não tiveram oportunidade, pois dificilmente encontram-se tais cursos na região. Além disso, de acordo com as apresentações e participações em eventos pode-se notar uma aprovação consideravel do público, por tratar-se um projeto que visa oferecer 
total suporte para os alunos participarem do mercado de jogos, que está em constante evolução. Através dos cursos pode-se perceber o desenvolvimento pessoal e profissional dos alunos em relação ao trabalho em equipe, comunicação e responsabilidade. Outro ponto importante, está relacionado a implementação de um sistema IoT, que possui uma grande relevância dentro do trabalho, pois garante a fácil atualização do projeto, permitindo assim acompanhar sempre as novas tecnologias envolvidas na área, trazendo mais praticidade, além de propiciar uma melhor visão de suas métricas, gerando um apoio ainda maior para os desenvolvedores.

\section{Referências}

Bender, W. N. (2015). Aprendizagem baseada em projetos: educação diferenciada para o século XXI. Penso Editora.

Bomfoco, M. A. and de Abreu Azevedo, V. (2012). Os jogos eletrônicos e suas contribuições para a aprendizagem na visão de jp gee. RENOTE, 10(3).

Fardo, M. L. (2013). A gamificação aplicada em ambientes de aprendizagem. RENOTE, 11(1).

Rapkiewicz, C. E., Falkembach, G. A. M., Seixas, L. M. J. d., Santos, N. d. S. R. S., Cunha, V. V. d., Klemann, M., et al. (2007). Estratégias pedagógicas no ensino de algoritmos e programação associadas ao uso de jogos educacionais. RENOTE: revista novas tecnologias na educação [recurso eletrônico]. Porto Alegre, RS.

Savi, R. and Ulbricht, V. R. (2008). Jogos digitais educacionais: benefícios e desafios. Renote, 6(1).

Silva, L. F., Pinheiro, M. D., Santos, R. R. d., and Schimiguel, J. (2016). O crescimento dos jogos no mercado mobile e suas acessibilidades. Revista Caribeña de Ciencias Sociales, (2016_02). 